\title{
INFLUENCE OF THE PROCESS IN SHYNTESIS OF FE-DOPED SNO2 NANOSIZED
}

\author{
Ribeiro, T. S. ${ }^{1}{ }^{*} ;$ Vasconcelos, I. F. ${ }^{1}$ \\ ${ }^{1}$ Departamento de Engenharia Metalúrgica e de Materiais, Universidade Federal do Ceará,Fortaleza, Ceará, Brasil \\ *tsribeiro.ufc@gmail.com
}

\begin{abstract}
Structural characterization of nanosized Fe-doped semiconducting oxide $\mathrm{SnO}_{2}$ is reported. Samples of $\mathrm{Sn}_{1-\mathrm{x}} \mathrm{Fe}_{\mathrm{x}} \mathrm{O}_{2-\mathrm{y}}$ (with $x=0.01,0.03,0.05,0.07$ and 0.10 ) were processed by a high energy mechanical milling and by a proteic sol-gel method. The samples are characterized by X-ray diffraction (XRD) and Mössbauer spectroscopy (EM). The analyses of the diffractograms revealed that all compounds presented the tetragonal rutile structure expected for $\mathrm{SnO}_{2}$, suggesting that $\mathrm{Fe}^{3+}$ were incorporated into the tin dioxide crystalline lattice. No impurity phases were detected by these techniques. Lattice parameters obtained by Rietveld refinement of XRD patterns reinforces the finding that doping ions are incorporated into the crystalline matrix substituting $\mathrm{Sn}^{4+}$ ions. In the process proteic sol-gel method the crystallinity of the powders increase with increase $x$ content. Residual microstrain, to samples processed by a high energy mechanical milling, was found to increase with iron content giving way to the conclusion that broadening of diffraction peaks are mostly due to increasing microstrain as a function of iron doping. Room temperature transmission Mössbauer spectroscopy results on Fe-based compounds showed the existence of two $\mathrm{Fe}^{3+}$ paramagnetic doublets consistent with distorted octahedral sites. It has been found the presence of oxygen deficient iron sites, in the samples processed by ball attributed to the stoichiometric unbalance of precursor materials used in the milling process.
\end{abstract}

